\section{Pacific Northwest}

National Laboratory

Operated by Battelle for the

U.S. Department of Energy

\title{
High Resolution Imaging of Vadose Zone Transport Using Crosswell Methods
}

Ernest L. Majer

Kenneth H. Williams

John E. Peterson

Lawrence Berkeley National Laboratory

Glendon W. Gee

Vadose Zone Transport Field Study Project Manager

July 1, 2001

Prepared for the U.S. Department of Energy

under Contract DE-AC06-76RL01830 


\section{DISCLAIMER}

This report was prepared as an account of work sponsored by an agency of the United States Government. Neither the United States Government nor any agency thereof, nor Battelle Memorial Institute, nor any of their employees, makes any warranty, express or implied, or assumes any legal liability or responsibility for the accuracy, completeness, or usefulness of any information, apparatus, product, or process disclosed, or represents that its use would not infringe privately owned rights. Reference herein to any specific commercial product, process, or service by trade name, trademark, manufacturer, or otherwise does not necessarily constitute or imply its endorsement, recommendation, or favoring by the United States Government or any agency thereof, or Battelle Memorial Institute. The views and opinions of authors expressed herein do not necessarily state or reflect those of the United States Government or any agency thereof.

PACIFIC NORTHWEST NATIONAL LABORATORY

operated by

BATTELLE

for the

UNITED STATES DEPARTMENT OF ENERGY

under Contract DE-AC06-76RL01830 


\section{High Resolution Imaging of Vadose Zone Transport Using Crosswell Methods}

Ernest L. Majer

Kenneth H. Williams

John E. Peterson

Lawrence Berkeley National Laboratory

Glendon W. Gee

Vadose Zone Transport Field Study Project Manager

Pacific Northwest National Laboratory

July 1,2001

Prepared for the U.S. Department of Energy

under Contract DE-AC06-76RL01830

Pacific Northwest National Laboratory

Richland, Washington 99352 


\section{Contents}

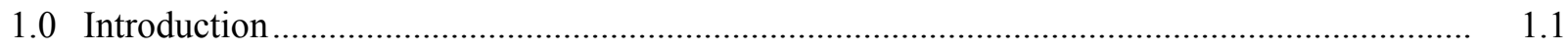

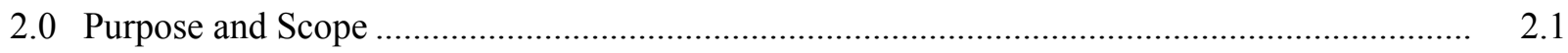

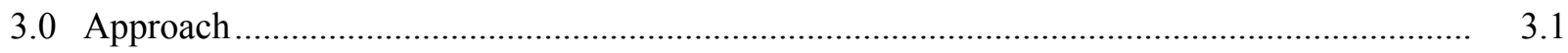

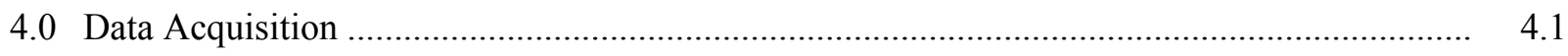

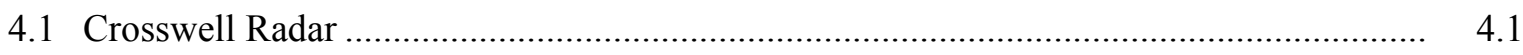

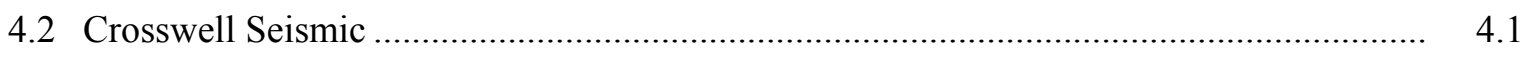

4.3 Ground Penetrating Radar ................................................................................. 4.1

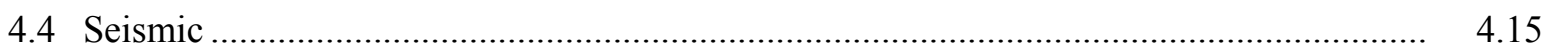

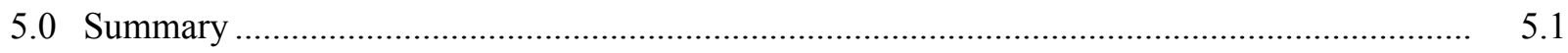

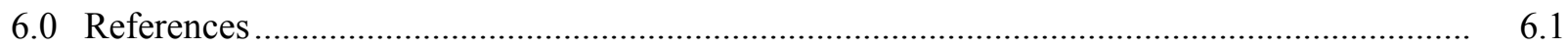

\section{Figures}

3.1. Well Array at the Sisson and Lu Test Site in the 200 East Area at Hanford ......................... 3.2

3.2. Cut-Way View of Test Site Showing Well Layout ............................................................... 3.3

4.1. Radar Results from the 2000 Pre-Injection Tests Between the Different Well Pairs .............. 4.2

4.2. The Top Figure Shows the Close Comparison Between the Moisture Estimation from Radar Data and the Estimation from Neutron Probe Data; The Bottom Figure Shows the Fit of the Data Using Topp's Equation ........................................................................... 4.4

4.3. Moisture Content Between Wells X2 and X3 from the Radar and Neutron Data .................. 4.6

4.4. Changes in Water Content After the First Water Injection in 2000 ..................................... 4.7

4.5. Changes in Moisture Content After the Second Injection in 2000 ....................................... 4.8

4.6. Changes in Moisture Injection During the Fifth Injection in 2000 ...................................... 4.9

4.7. Change in Water Content 2 Weeks After the Fifth Injection in 2000................................. 4.10

4.8. The Residual Water Content a Few Weeks After the Completion of the 2000 Columbia River Water Injections ............................................................................................. 4.11

4.9. The Difference in Radar Velocity Between the 2000 and 2001 Background Surveys............ $\quad 4.12$

4.10. Time-Lapse Images of Change in Radar Velocity Between Wells X1 and X2 During the Initial Release of Sodium Thiosulfate in 2001 .......................................................................

4.11. A Side-by-Side Comparison of the 2000 and 2001 Data...................................................... 4.14

4.12. Change in Radar Velocities from the Baseline (2001) Between all Well Pairs After the Injection of all of the Sodium Thiosulfate.

4.13. Change in Radar Velocities from the Baseline (2001) Between all Well Pairs 9 Days After the Injection of all of the Fluids (sodium thiosulfate plus the follow-on river water injections). 
4.14. The Definition of Structure from Radar and Seismic; Note the Much Greater Details in the Structure Derived from the Seismic.....

4.15. The Frequency Response as a Function of Time for the Seismic Source Used in the Large Offset Wells.

4.16. Example of Seismic Data at $19 \mathrm{~m}$ Through the Upper Vadose Zone Using a Seismic Source in the Range of 50 to 300 hertz. 


\subsection{Introduction}

This work addresses the need to have accurate predictive models for transport in the vadose zone. Crosswell methods are designed to provide a detailed understanding of how the physical properties (layering, lithology, etc.) affect the transport of fluids. Understanding contaminant migration through the vadose zone has not only been hampered by inadequate conceptual models, but has suffered from inadequate monitoring technologies. In the past, contaminant plumes at Hanford have most often been mapped with gross and spectral gamma logging tools. Migration was documented by observing changes in gamma logs that failed to fully describe the contaminant plume since the dominant gamma emitters (e.g., ${ }^{137} \mathrm{Cs},{ }^{90} \mathrm{Sr}$ ) are reactive and hence retarded in Hanford sediments, while non-reactive contaminants such as technetium, tritium, and nitrate, move readily with the water. The inability to track highly mobile species through the vadose zone highlights an important need, namely, methods other than gamma logging to describe the complete vadose-zone plume and to determine processes controlling accelerated contamination of groundwater at Hanford.

The main questions addressed with the crosswell methods are:

- What parts of the vadose zone-groundwater system control flow geometry?

- What physics control flow and transport in unconsolidated soils of the vadose zone?

- What is the optimum suite of field tests and laboratory studies to provide information for predicting flow and transport behavior?

- How can the information obtained during site characterization be used for building confidence in predictive numerical models?

Fully developed, the application of geophysics at Hanford should enable contaminant distributions to be located. Questions addressed were the sensitivity, resolution, and accuracy of the crosswell methods to derive the spatial and temporal distribution of properties controlling transport and contaminant distribution between and away from boreholes and the surface. Implicit in this activity is that geophysical methods will be used to extrapolate and extend measurements made at the point scale to the volumetric scale. Also implied will be that the methods will be applied to derive static as well as dynamic properties to define flow processes as well as intensive properties. In a broad sense, the research focuses on the capability of the geophysical methods to define as well as separate the natural complexity and heterogeneity of the subsurface from that created by the contaminants.

Examples of specific applications are

(1) Change in moisture content in the vadose zone

(2) Degree of continuity/thickness of lithologic units in the vadose zone (Hanford sands, plio-pleistocene caliche, upper Ringold sands, Ringold gravels, etc.

(3) Location and distribution of heterogeneities within the lithology (sills, clastic dikes, fractures/faults, fracture orientation/density, etc.)

(4) Matrix and fracture properties of units (porosity, grain-size distribution, moisture distribution, mineral composition, etc.).

(5) Location and extent of contaminant plumes that may have an anomalous chemical or physical signature (precipitation/alteration products, secondary deposition, etc.)

(6) Location of "fast paths" affecting transport (natural and contaminant induced). 


\subsection{Purpose and Scope}

To date, there have been two major injection events at the Scisson and Lu site, one in 2000 that used Columbia River water and one in 2001 that used a saline solution (density of $1.3 \mathrm{~g} / \mathrm{cc}$ ) chased by Columbia River water. The primary purpose of the crosswell radar and seismic imaging is to provide detailed information on the lithology and structure $(25 \mathrm{~cm}$ or less resolution) as well as provide the same level of detail on the location of the fluid during and after injection. A second purpose is to evaluate these methods and/or modify the methods to determine their use at the tank-farm scale. The radar methods are being applied in a time-lapse sense to determine changes in the moisture content; thus, repeated measurements were made at the same sites. The seismic measurements were designed to examine structural and lithologic heterogeneity, and thus they were used only once after the injections were complete. We assumed before we applied the seismic measurements that they would be less sensitive to fluid content; however, as will be seen below, the seismic measurements may have high enough frequency content and resolution to provide valuable independent information from the electrical measurements.

As was stated in the initial test plan, a common goal among the projects is to collect field data and develop conceptual models of vadose-zone flow and transport. Also, the capability to identify changes from the baseline also demands the identification of advanced technologies capable, not only of using the existing infrastructure to detect contaminants, but also of locating in situ the high-risk, often difficult-todetect contaminants using surrogate measurements. A major challenge lies in extrapolating results over multiple spatial scales and from one site to the next. In heterogeneous environments, such extrapolation can only be accomplished after the spatial-scale dependence of flow and transport properties and known. Thus, the crosswell seismic and radar were designed to address these fundamental goals as well as the more practical goals of use some day at the tank farm scale. 


\subsection{Approach}

Figure 3.1 shows a plan view of the well configuration at the Sisson and Lu test site with the wells marked as " $x$ " like the wells used for the crosswell radar and seismic studies. These wells were located based on the past experience of the most likely location of flow during the new injection experiments. Figure 3.2 shows a cut-away view of the test site and well layout with a conceptual diagram of how flow took place during the last experiments. In the previous experiments, an injection well was placed in the center of the well field and was surrounded by 32 observation wells. The wells were constructed from three 20 -ft sections and one 5-ft section of 6-in.-diameter Schedule 40 steel casing. The sections were welded together to form watertight joints reinforced with four steel straps welded symmetrically around the casing. During installation, the 5-ft section of casing was driven into the soil, and then the $20-\mathrm{ft}$ section was welded on and the driving was continued until the top of the casing was beyond the reach of the drive hammer. Soils with the casing (drill cuttings) were removed by advancing $20 \mathrm{ft}$ with a rotary by using air as a drilling fluid. Cuttings were blown out of the casing and collected near the point of drilling. Samples were collected of these cuttings and stored in containers, and selected samples were later analyzed for hydraulic properties. In the present case, the X wells were PVC cased (2-in. I.D.) and emplaced with cone penetrometer technology. The crosswell methods were used to monitor the simulated leak injections of both the 2000 and 2001 injections. In 2000, the injections were in 4000-L increments of Columbia River water over a 6 -week period. In 2001, the injections were five increments of approximately 4000-L of sodium thiosulfate over a 5-week period, followed by three 4000-L injections of Columbia River water. In 2000, the crosswell data were combined with the neutron logging results in the steel-cased wells. The measurement focus was to determine the state variables controlling water movement (i.e., water content, physical heterogeneities, and, if possible, water potential, chemical concentrations, and temperature). It was also desired to determine if the density of the fluid would change the flow behavior. 


\section{Legend}

Adv.Tensiometer Nest (Augered)

Adv. Tensiom eter Nest (CPT)

- Cross-Borehole Access

ERT Array

- New Injection Point

Subsurface Radiation Zone

- Split-spocn Cores

O Steel-cased Well

Figure 3.1. Well Array at the Sisson and Lu Test Site in the 200 East Area at Hanford. The shaded area beteen X1, X2, X3, and X4 was the target area for the crosswell. 


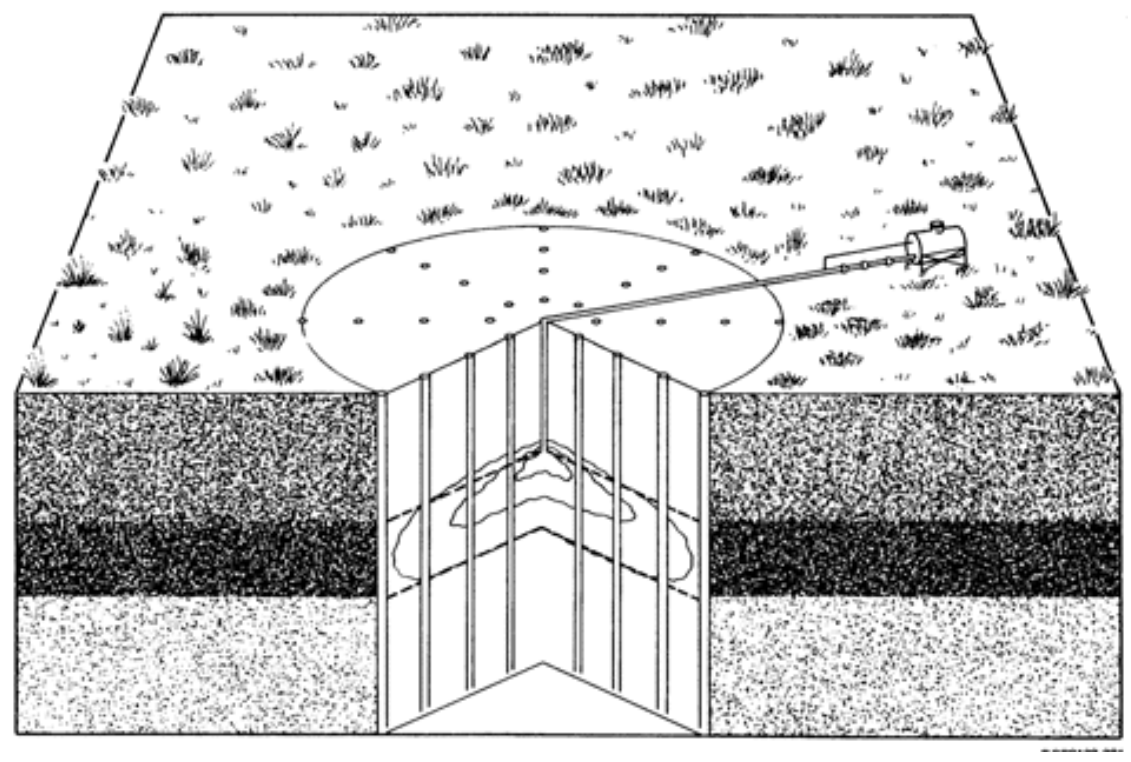

Figure 3.2. Cut-Way View of Test Site Showing Well Layout 


\subsection{Data Acquisition}

\subsection{Crosswell Radar}

The ground penetrating radar (GPR) work at Hanford consisted of repeated crosswell tomographic data sets being collected between the six possible well pairs at the Sisson-Lu site. These include X1-X2, $\mathrm{X} 2-\mathrm{X} 3, \mathrm{X} 3-\mathrm{X} 4, \mathrm{X} 1-\mathrm{X} 2, \mathrm{X} 1-\mathrm{X} 3$, and X2-X4. In 2000, a total of four data sets was collected, one before injection as a background data set, two during the injections, and one after the injections. In 2001, four data-collection visits were made to the site. These include the March 26-28 ${ }^{\text {th }}$ 2001(PRE) visit, which constituted the base line data set, followed by the monitoring of the initial release of $1900 \mathrm{~L}$ of sodium thiosulfate on March 30. The next data set was acquired on April 28 and 29 after 19,000 L of sodium thiosulfate had been injected (injection stopped on April 26). The last data set was collected on May 18, 2001, after $3785 \mathrm{~L}$ of a mixture of tank sludge and river water and $7570 \mathrm{~L}$ of Columbia River water had been injected (injection stopped on May 9, 2001). All of the radar data were collected using the Sensors $\&$ Software, Inc. PulseEKKO 100 GPR system using the $200-\mathrm{MHz}$ center-frequency antennas. The step size for data collection between all well pairs was $0.125 \mathrm{~m}$ in 2000 and $0.25 \mathrm{~m}$ in 2001 .

\subsection{Crosswell Seismic}

The crosswell seismic was collected after all of the infiltration tests were completed in both 2000 and 2001. This was because the wells used for the crosswell seismic had to be filled with water (this would not have to be the case in the tank farm; it just made it easier in this case) to provide good seismic coupling in the small PVC-cased wells. Because we did not know if the wells would leak, we did not want to have water into the formation during the infiltration tests. Until this experiment, it has been our experience that it is very difficult to collect high-resolution seismic data (in the kilohertz range) in a vadose zone geology. This is because partial saturation usually greatly attenuates seismic energy. In fact, until this experiment, we are not aware of any high-frequency seismic data collected at this scale in any vadose-zone environment. In 2000, there were four different seismic crosswell sections obtained, three high-resolution sections and one long offset section using a distant 6-in. steel-cased hole for a source hole. The three high-resolution sections were collected by placing a 24-element hydrophone array in Well X4, which was filled with water. A 1.5 -in.-diameter by 4-in.-long piezoelectric cylindrical seismic source was then used successively in Wells X3, X2, and X1. In 2001, only the high-frequency crosswell seismic data were collected. The data were collected in a tomographic sense at $0.25-\mathrm{m}$ intervals for both source and receiver. The piezoelectric source put out energy from 1 to 10 kilohertz. The long offset section was obtained by leaving the hydrophone array in Well X4 and placing an orbital vibrator source in Well 2E-24-110, which was also filled with water, approximately $19 \mathrm{~m}$ away from X4. The purpose of this was to see how far seismic energy could be transmitted in the vadose zone. The orbital vibrator is a much stronger source than the piezoelectric source, but puts out lower frequencies, in the 50- to 300-hertz range. Assuming that the resolution is on the order of $1 / 4$ wave length, and the velocities are on the order of $700 \mathrm{~m} / \mathrm{sec}$ (this is what we measured), then we were getting a possible resolution of $10 \mathrm{~cm}$ for the piezoelectric data and $60 \mathrm{~cm}$ for the orbital source (assuming 300 hertz for the orbital and 2000 hertz for the piezoelectric source).

\subsection{Ground Penetrating Radar}

Electromagnetic wave slownesses (the reciprocal of velocity) were estimated for this study using the travel times of the propagation waves and a straight-ray algebraic reconstruction inversion technique (Peterson et al. 1985). A velocity pixel dimension of $0.25 \times 0.25 \mathrm{~m}$ was used for the image inversion. 
Figure 4.1 shows the velocities obtained from the slowness values between all six well pairs before the tests in 2000 (initial conditions, before any water was injected).
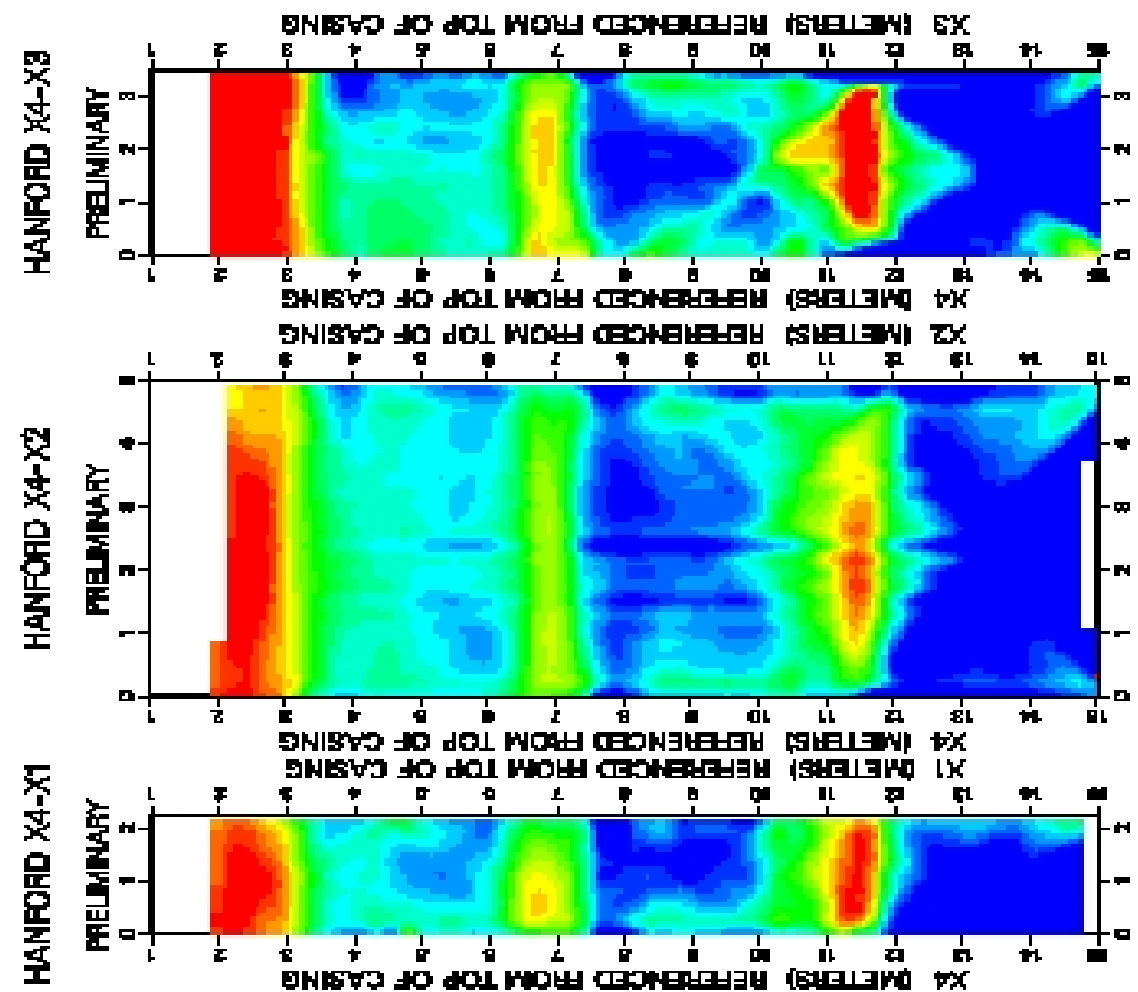

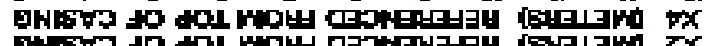
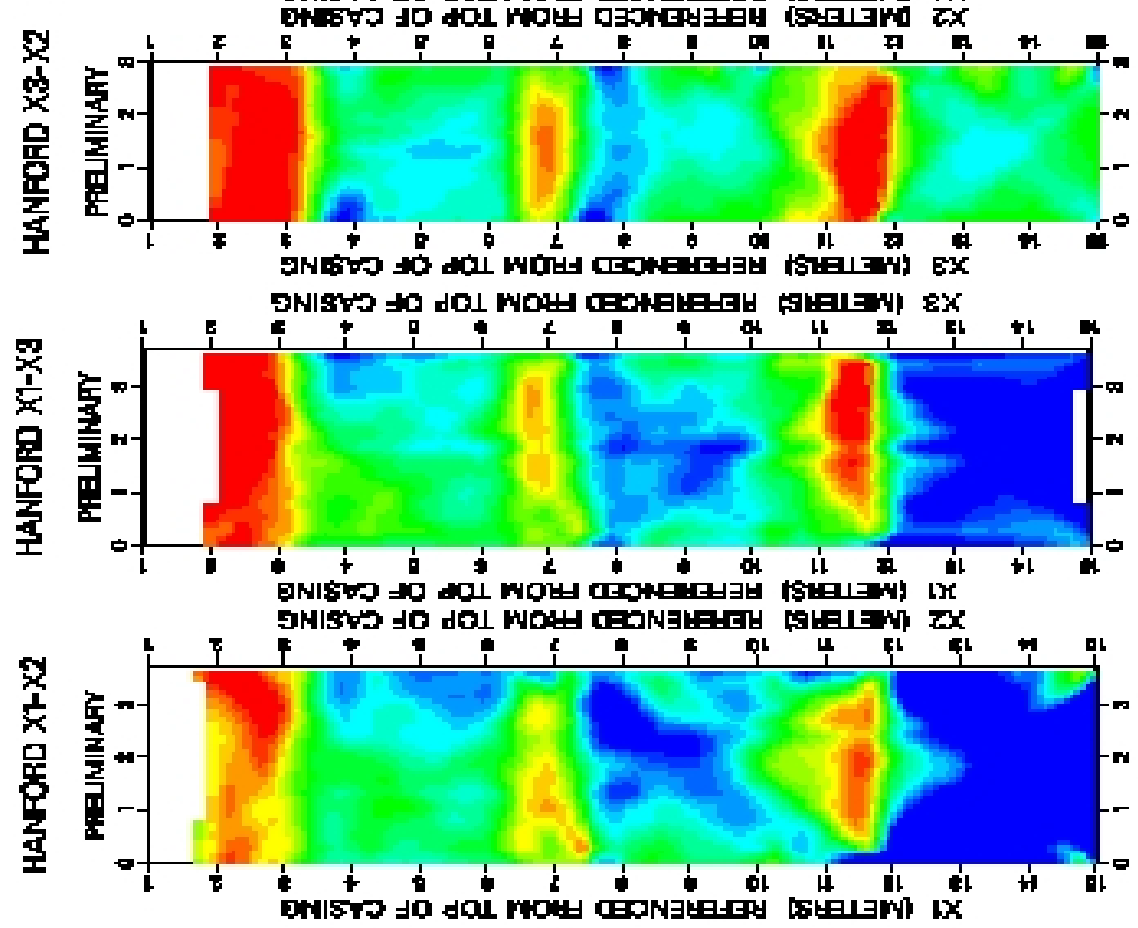

Figure 4.1. Radar Results from the 2000 Pre-Injection Tests Between the Different Well Pairs 
These data sets can be used to delineate the stratigraphic layering. The electromagnetic propagation velocity range observed on the tomograms of approximately 0.11 to $0.16 \mathrm{~m} / \mathrm{ns}$ is typical for unsaturated, unconsolidated sands.

The variation in radar velocity in unsaturated materials usually indicates variations in moistures or texture. The tomograms suggest the presence of six to seven distinct velocity layers, each continuous across the length of the tomogram and ranging in thickness from 0.25 to $3.5 \mathrm{~m}$. The layers alternate between higher and lower velocities with the shallowest layer having very low velocities $(<0.11 \mathrm{~m} / \mathrm{ns})$ and extending from the surface to about $3.0 \mathrm{~m}$ below ground surface (BGS). The next deeper layer is of higher velocity $(\sim 0.14 \mathrm{~m} / \mathrm{ns})$ and extends 3.0 to $3.5 \mathrm{~m}$ below the first layer to a depth of $\sim 6.5 \mathrm{~m}$. Some lateral velocity inhomogeneity is observed in this layer. The third layer consists of 0.25 to $0.50 \mathrm{~m}$ of low velocity material, which usually indicates which is higher in moisture content, i.e., a fine sand. While this layer is observed to be primarily flat, there appears to be some thickening or splitting of this layer near borehole X1. Another thin layer (Layer 4) 0.25 to $0.50 \mathrm{~m}$ thick, consisting of higher velocity material, suggests a more coarse grain material. This layer has velocities just slightly higher than the layer below it and can be best seen in the X3-X2 tomogram. The next deeper layer (Layer 5) is approximately $3.0 \mathrm{~m}$ thick with similar velocities to those of Layer 2, suggesting that it may be made up of similar material. Layer 6 is similar to Layer 3 in thickness, though slightly thicker $(0.50$ to $0.75 \mathrm{~m})$, and velocity. Below this is the final (seventh) layer, which exhibits the highest velocities $(>0.16 \mathrm{~m} / \mathrm{ns})$. These seven layers extend across the entire set of radar profiles.

The electromagnetic wave velocities $(v)$, obtained from the slowness estimates, can be converted to dielectric constant estimates ( $\kappa)$ using $\kappa=\frac{c^{2}}{v^{2}}$, where $c$ is the velocity of electromagnetic waves through air. Dielectric constants in geologic materials range from approximately 3 to 25 . As the dielectric constant of air is 1 and water is 80 , the water content will have the dominant effect on the dielectric constant of an unsaturated material. It is possible to convert the dielectric constant into estimates of water content using a variety of methods. A common method of conversion is through the use of Topp's curve, which is an empirical relationship between the dielectric constant and water content determined in the laboratory (Topp et al. 1980). The most direct and precise method is to correlate the field-scale dielectricconstant estimates obtained from the tomograms near the wells with co-located neutron probe measurements of water content. This was done in the 2000 study with the results for Well X3 shown in Figure 4.2a. This figure shows that there is good correlation in shape between the two curves, and thus the value of the dielectric constant derived from the velocities can be derived by calibrating against the neutron-log results. The neutron data are not yet available for 2001 to derive the results for the 2001 radar data, but the important thing to remember is that the more the water content, the slower the radar velocity. 


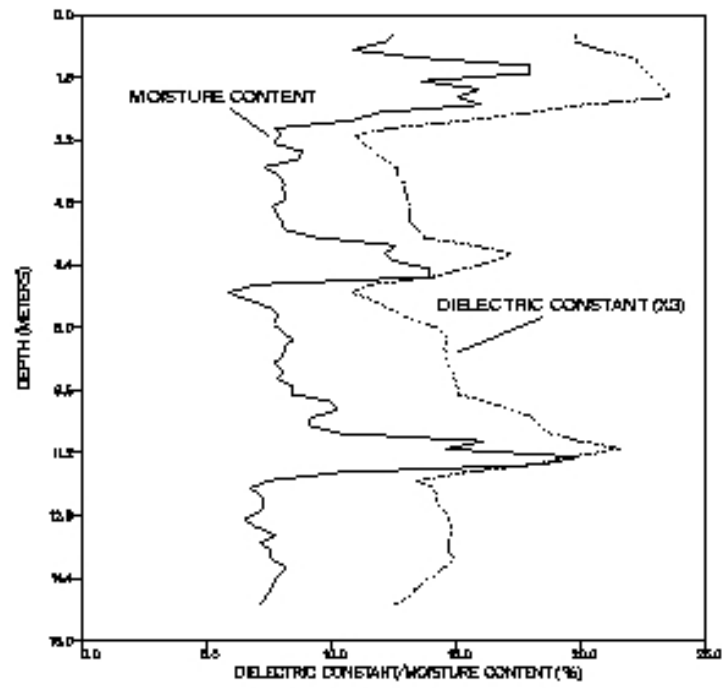

FIGURE 4A

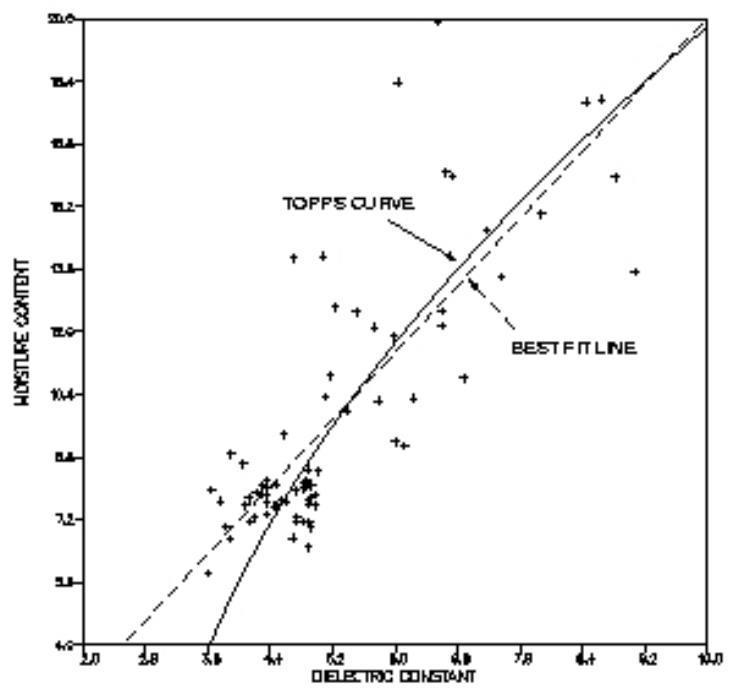

FGURE 4B

Figure 4.2. The Top Figure Shows the Close Comparison Between the Moisture Estimation from Radar Data and the Estimation from Neutron Probe Data; The Bottom Figure Shows the Fit of the Data Using Topp's Equation

As an example, Figure 4.3 shows the comparison of the moisture content derived from the radar data to the moisture content derived from the neutron data before the first river-water injection. This is assumed to be the water content between the wells. This result is for the 2000 data between Wells X2 and 
X3. It should be noted that the neutron data were not taken in these wells but close by. The neutron data are extrapolated to derive this image rather than directly sampled as in the case of the radar data. As can be seen, there is good spatial correlation between the neutron data and the radar results. Figure 4.4 shows an example of differencing the traveling times between the POST1 (acquired one week after the second injection) and the base line measurements (collected in May 2000). After inverting these differences, we can obtain an estimate for the change in radar properties. Because the geology remains constant, the observed change in dielectric constant should indicate the change in moisture. These estimates can be converted to the change in moisture content using the same site-specific petrophysical relationship discussed above. Figure 4.4 shows the changes in moisture content for three of the well pairs associated with POST1. The results indicate that the greatest changes in moisture occur just above the low moisture zone at $6.5 \mathrm{~m}$ in depth (Layer 3 ) and just above the low moisture feature at $10 \mathrm{~m}$ in depth (Layer 6). In fact, there appear to be no changes in moisture (or retention in water content) below $10 \mathrm{~m}$. These data suggest that, at the time of this tomogram ( 2 weeks after Injection 1 and 1 week after Injection 2), only a small amount of water had flowed (or been retained) into the area sampled by the X4-X3 well pair, which is about $3.5 \mathrm{~m}$ laterally from the injection point. These changes in moisture content can be compared to the neutron-probe water-content values as illustrated in Figure 4.5. Although the neutron-probe values are not "differenced" in this figure, a comparison of these values (POST1) with the neutron-probe data collected in May 2000 (Figure 4.3) indicate that moisture-content changes detected by the neutron probe correspond to these changes indicated by the tomogram.

POST2 data were acquired during Injection 5 in an attempt to image any change in moisture distribution over the duration of a single injection. Data were acquired only between well pairs X2-X1, the well pair closest to the injection point. Three complete data sets were acquired between these well pairs at discreet intervals after approximately 150, 400, and 900 gal were released. The data were all subtracted from the baseline measurement acquired the afternoon before the Injection 5 release. After inverting these data, the slownesses were used to estimate changes in water content as described earlier. The change in moisture content, shown in Figure 4.6, suggests that during the time of active injection, the fluid spreads horizontally above the Layer 3 low-moisture zone, and no change in moisture is observed in, or below, this layer during the time of injection. POST3 data were acquired 2 weeks after Injection 5, the final injection of fluid. The data were differenced from the May baseline measure, and the changes in moisture content are shown in Figure 4.7. The regions of increased moisture above Layer 2 and Layer 5 are still observed. However, some moisture increase can now be observed below this level to about 11.5 to $12 \mathrm{~m}$ BGS. 


\section{BASELINE DATA}

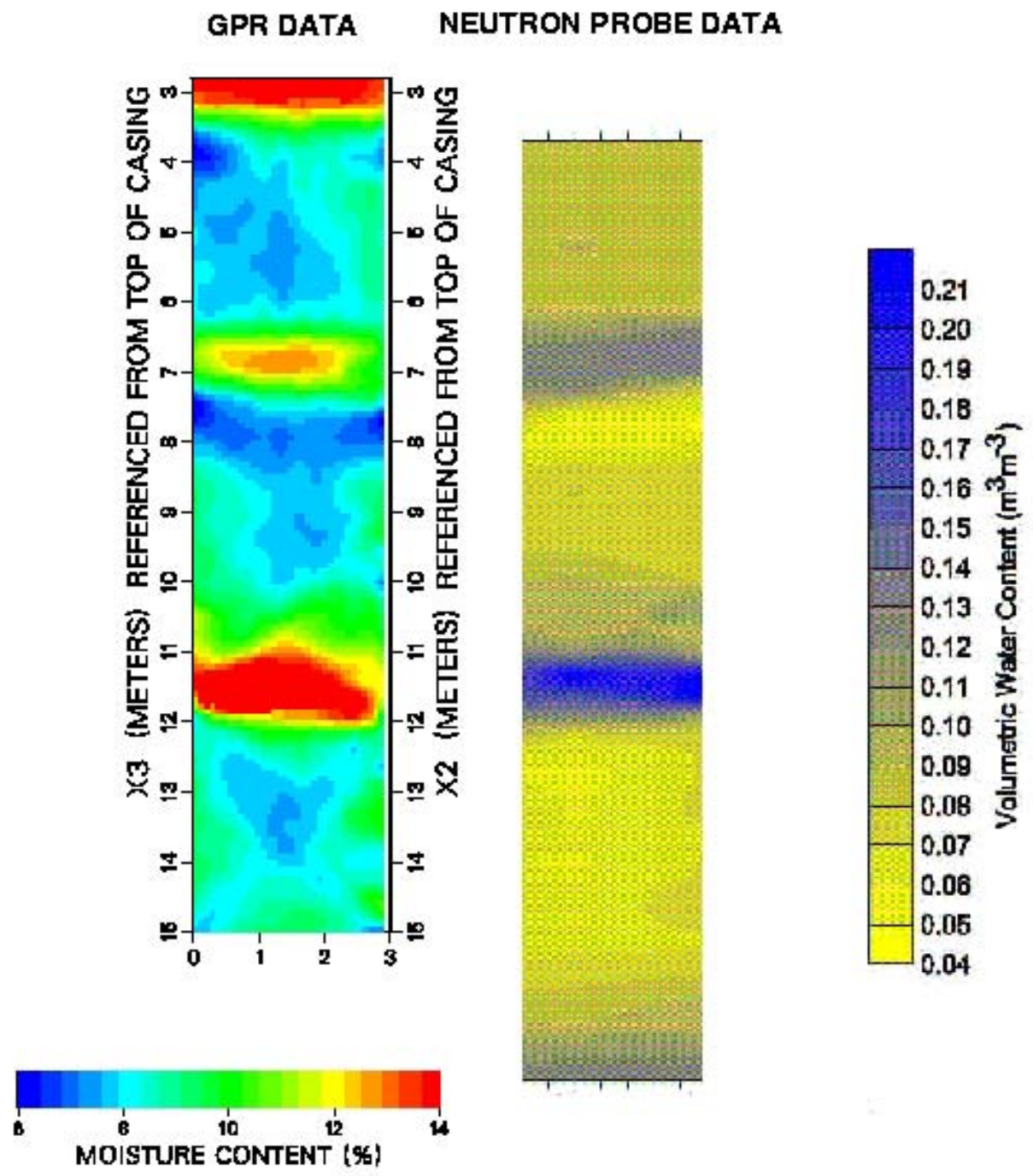

Figure 4.3. Moisture Content Between Wells X2 and X3 from the Radar and Neutron Data 
POST1 MOISTURE CONTENT CHANGES

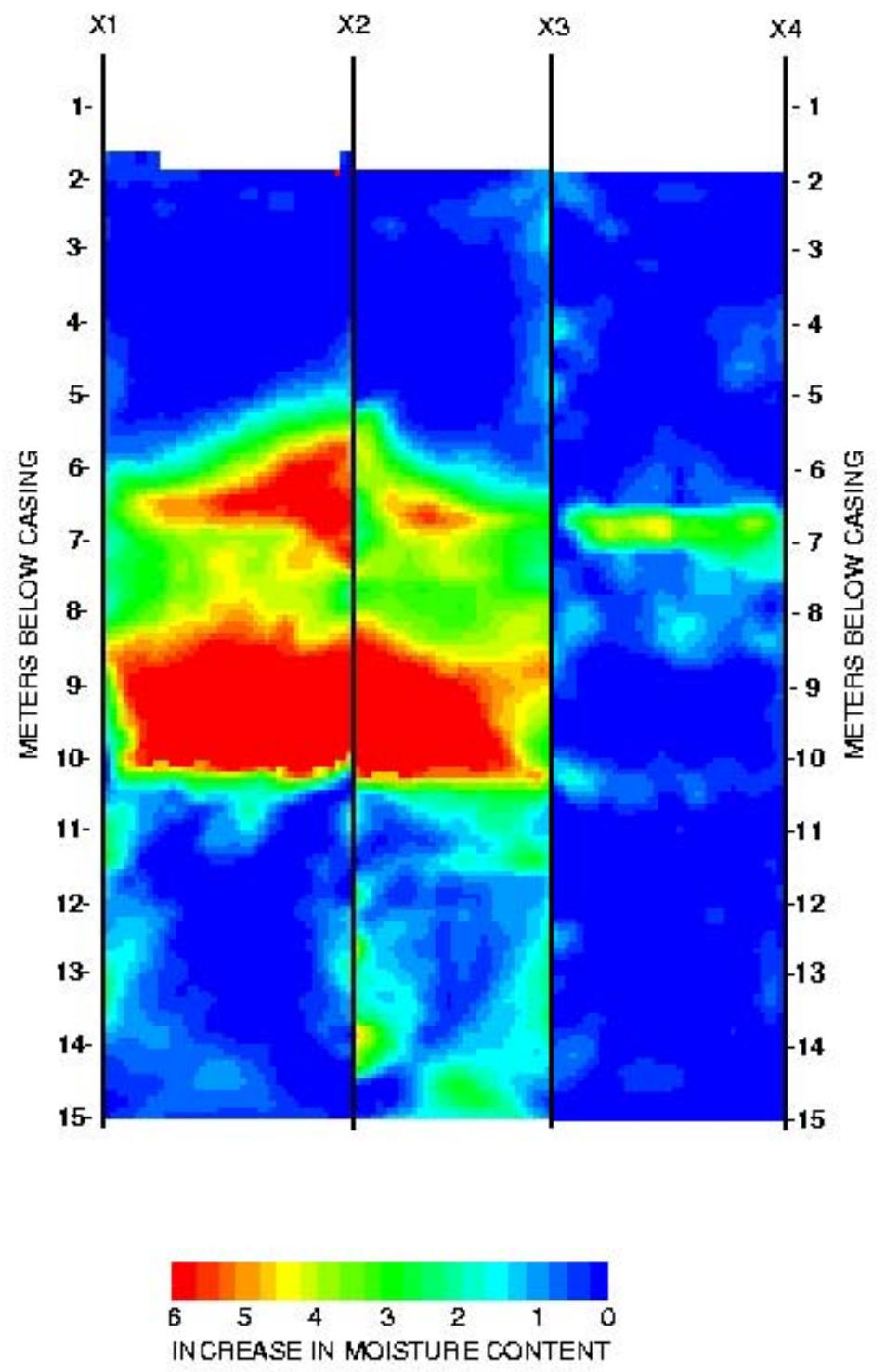

Figure 4.4. Changes in Water Content After the First Water Injection in 2000 


\section{POST INJECTION 2}

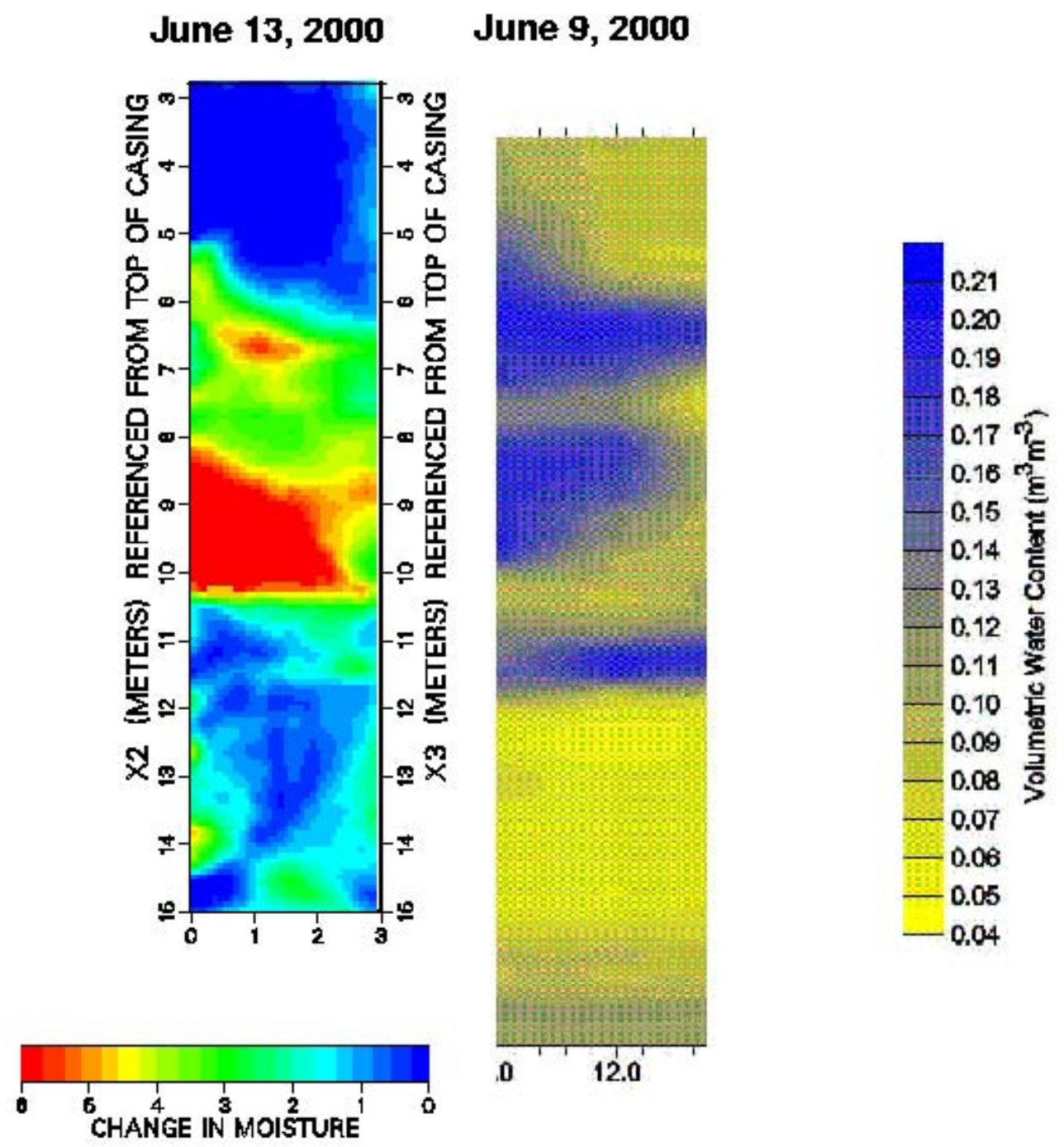

Figure 4.5. Changes in Moisture Content After the Second Injection in 2000 


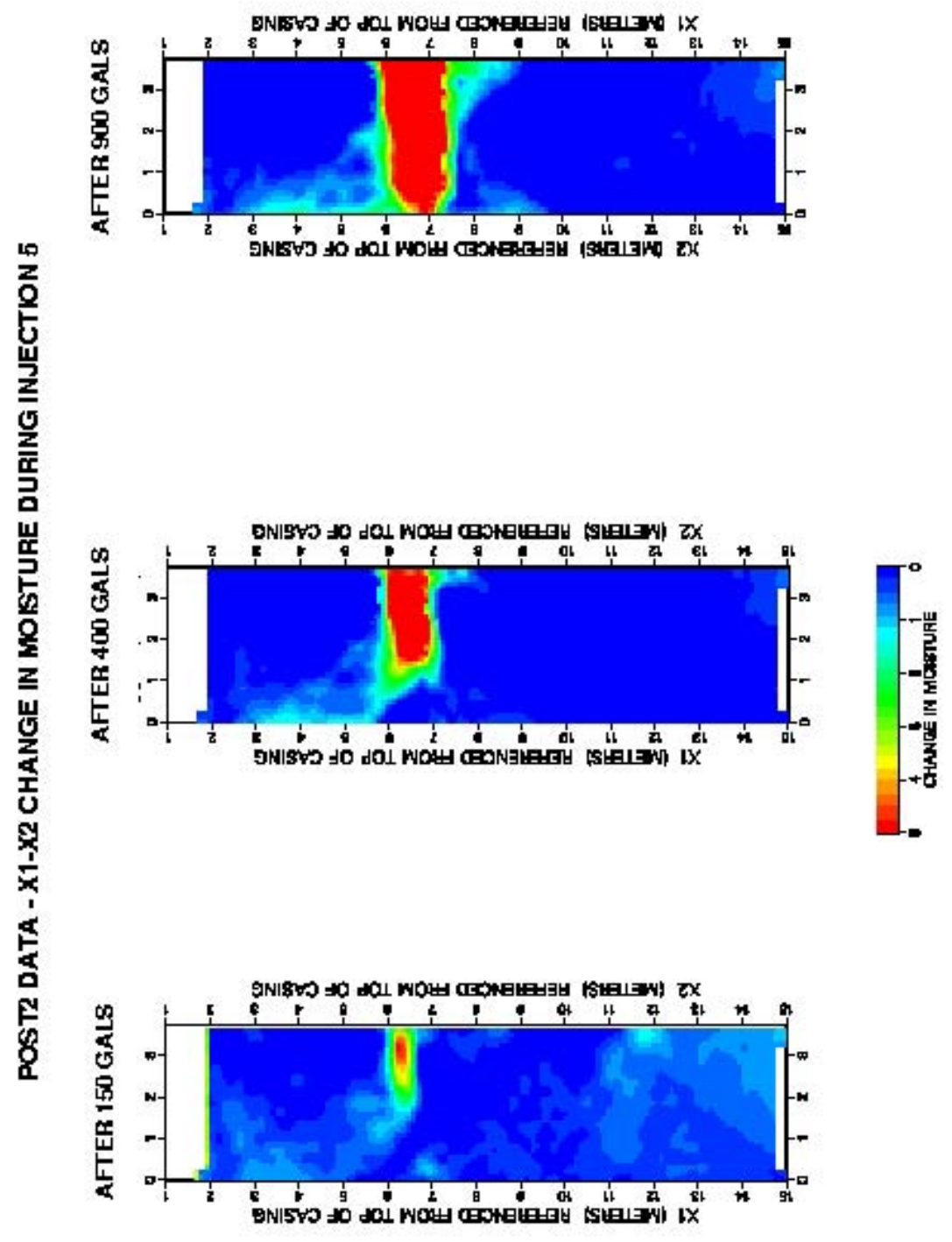

Figure 4.6. Changes in Moisture Injection During the Fifth Injection in 2000 
POST3 MOISTURE CONTENT CHANGES
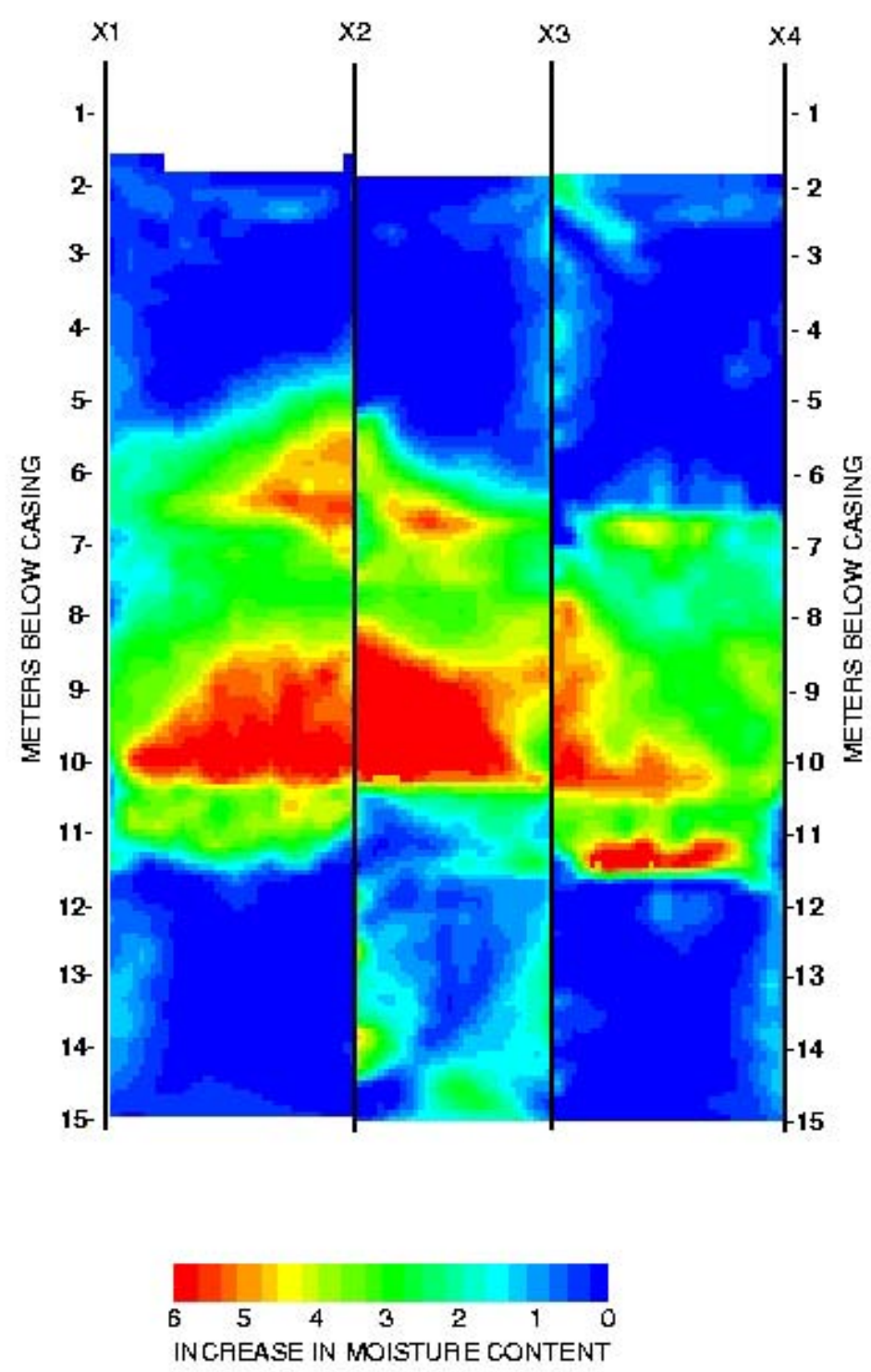

Figure 4.7. Change in Water Content 2 Weeks After the Fifth Injection in 2000

Figure 4.8 shows the residual water content in the formation after all of the 2000 injections were completed. As can be seen, there was no residual water content beneath $11.5 \mathrm{~m}$. This is the bottom of the fine grain layer. This agrees with the tracer work carried out by LBNL in that no tracers were detected below this layer also (personal communication, Mark Conrad, LBNL). 


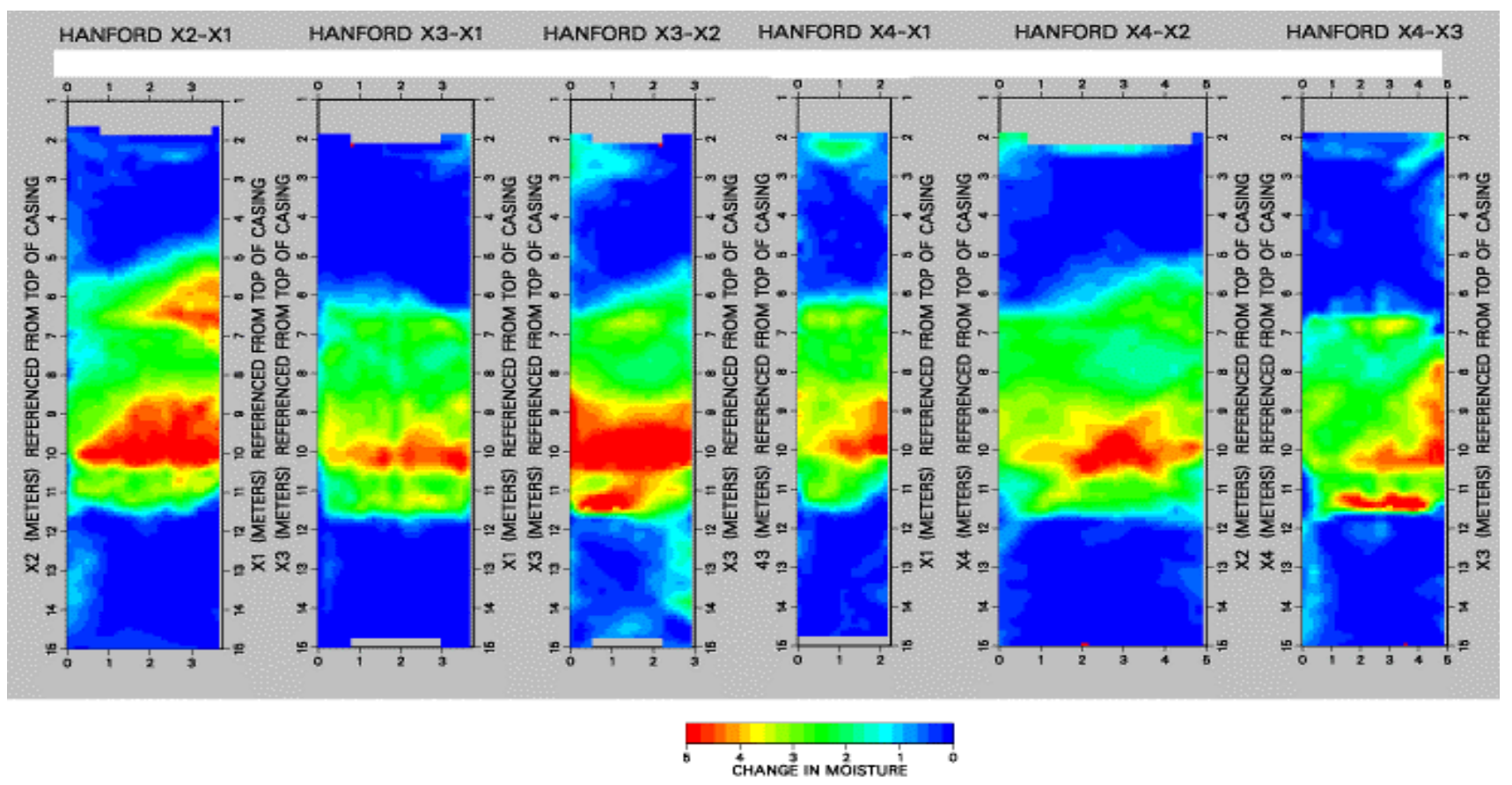

Figure 4.8. The Residual Water Content a Few Weeks After the Completion of the 2000 Columbia River Water Injections

Figure 4.9 shows the radar velocity change between the initial survey in 2000 (the background survey before any water was injected in 2000) and the initial survey in 2001. This is a measure of how much extra moisture remained in the formation at the time just before the 2001 experiment, presumably due to the 2000 release. It should be noted that the negative change (red in Figure 4.9) below the $11.5 \mathrm{~m}$ in depth is real but exaggerated. It is indicated that some moisture did eventually migrate below the $11.5 \mathrm{~m}$ depth, mainly only near X2 and X3. This moisture may have been introduced when the X holes were filled with water for the seismic survey; the holes did leak, but there was no way of knowing where the leaks were.

The radar work was done slightly differently in 2001 than in 2000. In 2001, we wanted to obtain a time-lapse measurement as soon as possible to determine if the heavier sodium thiosulfate was flowing in the same manner as the river water did in 2000. There was also a hypothesis that the sodium thiosulfate would be affected by the moisture (or residual water content) in the ground.

Figure 4.10 is a time-lapse radar image of the change in radar velocity between Wells X1 and X2 after 170, 420, and 500 gal of sodium thiosulfate were injected. Compare these results in Figure 4.10 with Figure 4.6. 

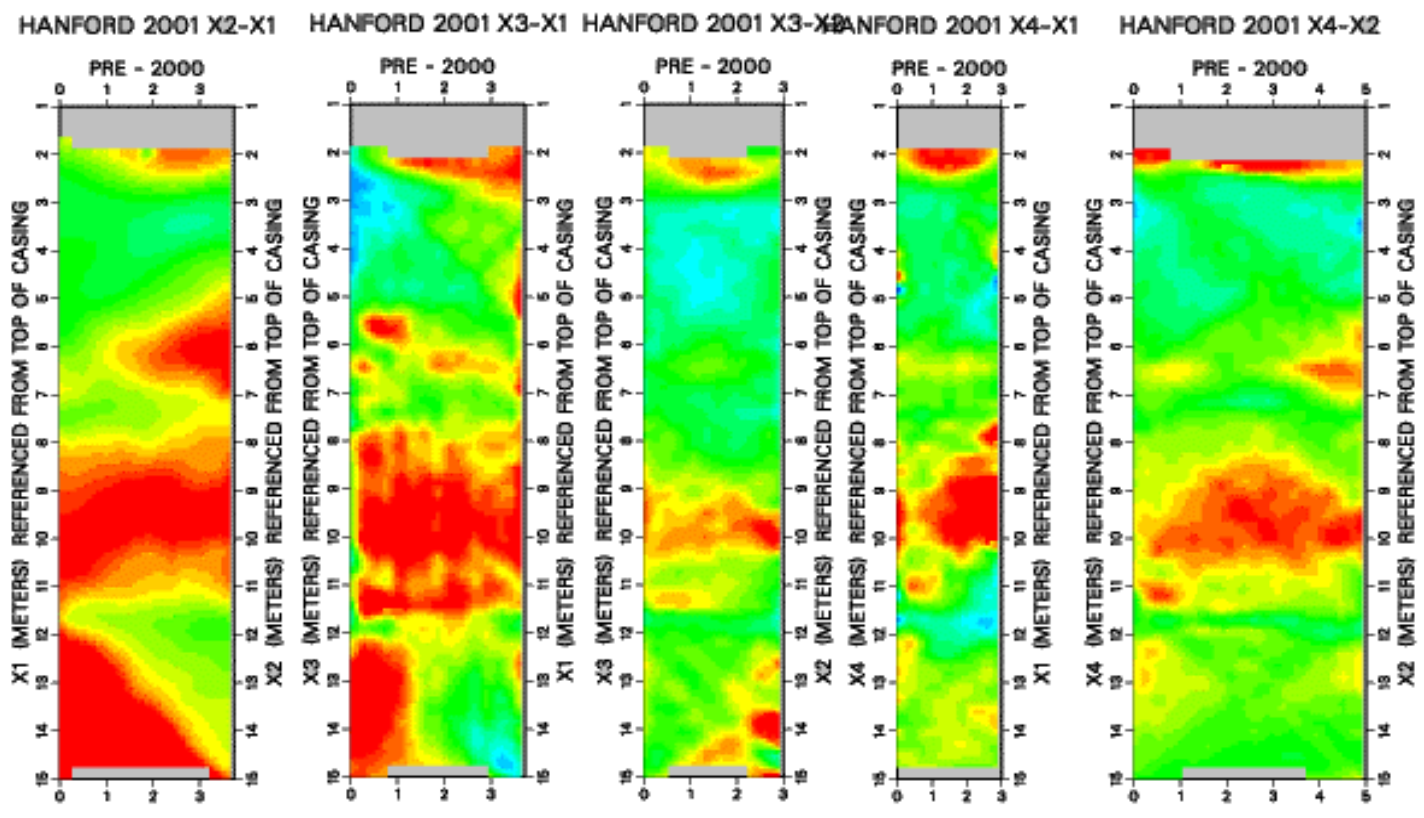

HANFORD 2001 X4-X3

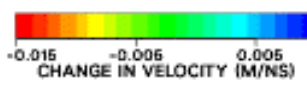

JOHN E. PETERSON

Figure 4.9. The Difference in Radar Velocity Between the 2000 and 2001 Background Surveys 
Initial Release (2001), sodium thiosulfate:

$$
\begin{aligned}
& \text { X1-X2: } \text { P1 - after } \sim 170 \text { gal } \\
& \text { P2 - after } \sim 420 \text { gal } \\
& \text { P3 - after } \sim 500 \text { gal }
\end{aligned}
$$

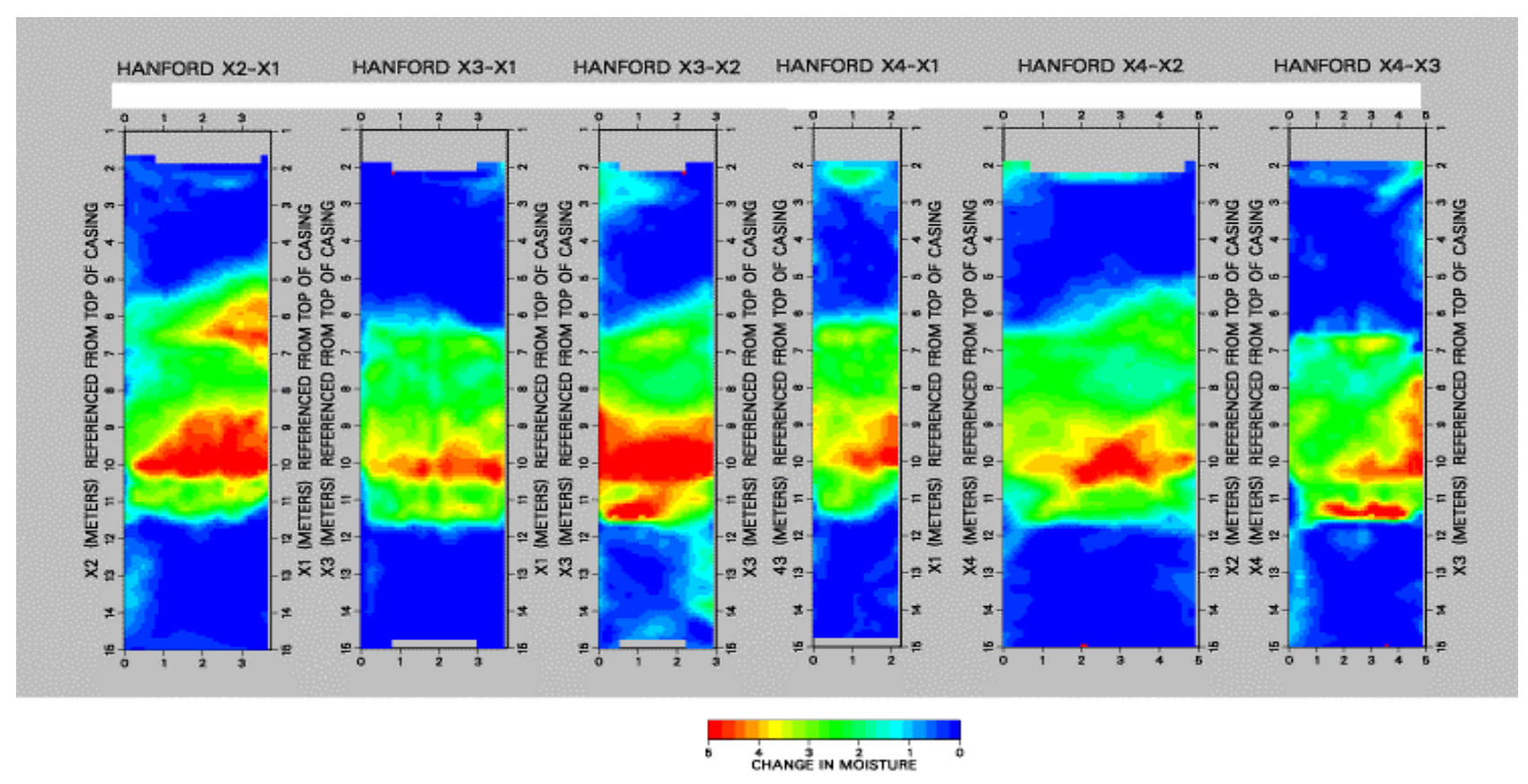

Figure 4.10. Time-Lapse Images of Change in Radar Velocity Between Wells X1 and X2 During the Initial Release of Sodium Thiosulfate in 2001 
It should be noted that the injection was at $5 \mathrm{~m}$ in depth about $1 / 2 \mathrm{~m}$ behind the plane of $\mathrm{X} 1$ to $\mathrm{X} 2$ at about $1 \mathrm{~m}$ from Well X2. Figure 4.11 shows the results of 2000 and 2001 side by side after 500 gal for each. As can be seen, the two are quite different. In 2000, the river water appears to have gone straight down to the boundary of the fine-scale layer, and then traveled across the layer in a horizontal manner. In 2001, it seems that the more viscous sodium thiosulfate did not go straight down but traveled horizontally towards X1, sank to the layer below, and then went downgradient (perpendicular to the plane of X1 and $\mathrm{X} 2$ ).

\section{Comparison of 2000-01 Data for X1-X2 ( 500 gal)}
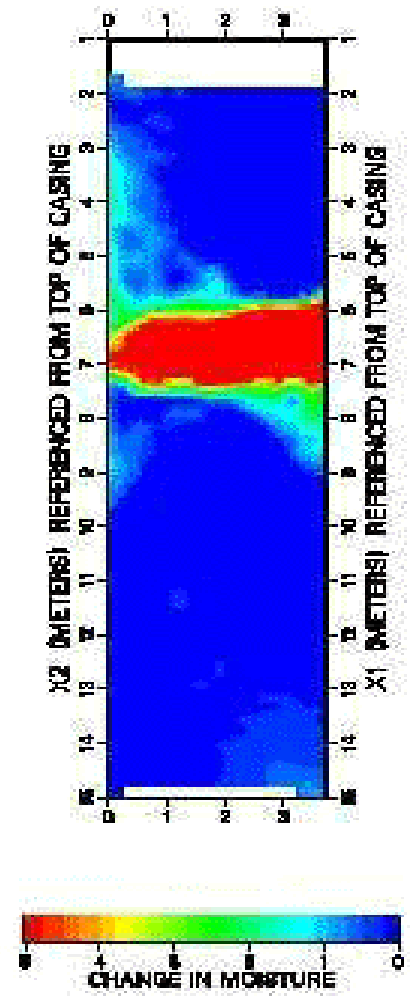
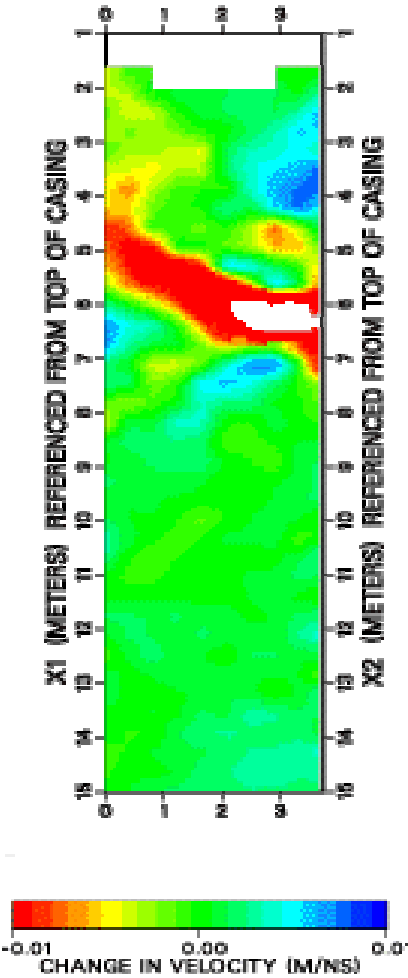

Figure 4.11. A Side-by-Side Comparison of the 2000 and 2001 Data. The injection point was about $1 / 2 \mathrm{~m}$ behind the image plane at $5 \mathrm{~m}$ depth and $1 \mathrm{~m}$ from Well X2.

The results of the later monitoring of the 2001 injections are shown in Figure 4.12 and Figure 4.13. As can be seen, the images are not as detailed as the 2000 images in the center of the images. This is because the very conductive sodium thiosulfate has such a pronounced detectability that it does not take much to slow down the radar signal and block it out. The gray areas are zones in which the signal was affected so strongly that we could not determine the velocity. The colors (red to green) have the same meaning as before, i.e., red indicates more fluid content than the baseline (2001) and green indicates no change from the baseline. Figure 4.12 presents data from the radar imaging after all of the sodium thiosulfate was injected. As in the case of the 2000 injection, it appears that there was no residual fluid below the $11.5-\mathrm{m}$ level, at least at the time of the radar survey, which was 2 days after stopping the injection of the sodium thiosulfate. Figure 4.13, however, is data that were recorded 9 days after the last injection sequence of fluid. This last sequence was 1000 gal of water that were used to clean out the tank holding the sodium thiosulfate (over $5 \mathrm{~h}$ on May 2, 2001) followed by 1000 gal of river water on May 3 and another 1000 gal of river water on May 9,2001, for a total of 3000 gal. Overall, 8030 gal of fluid 
were injected in 2001. Figure 4.13 shows that at 9 days after the last injection, the fluid became deeper than the 11.5 -m layer.

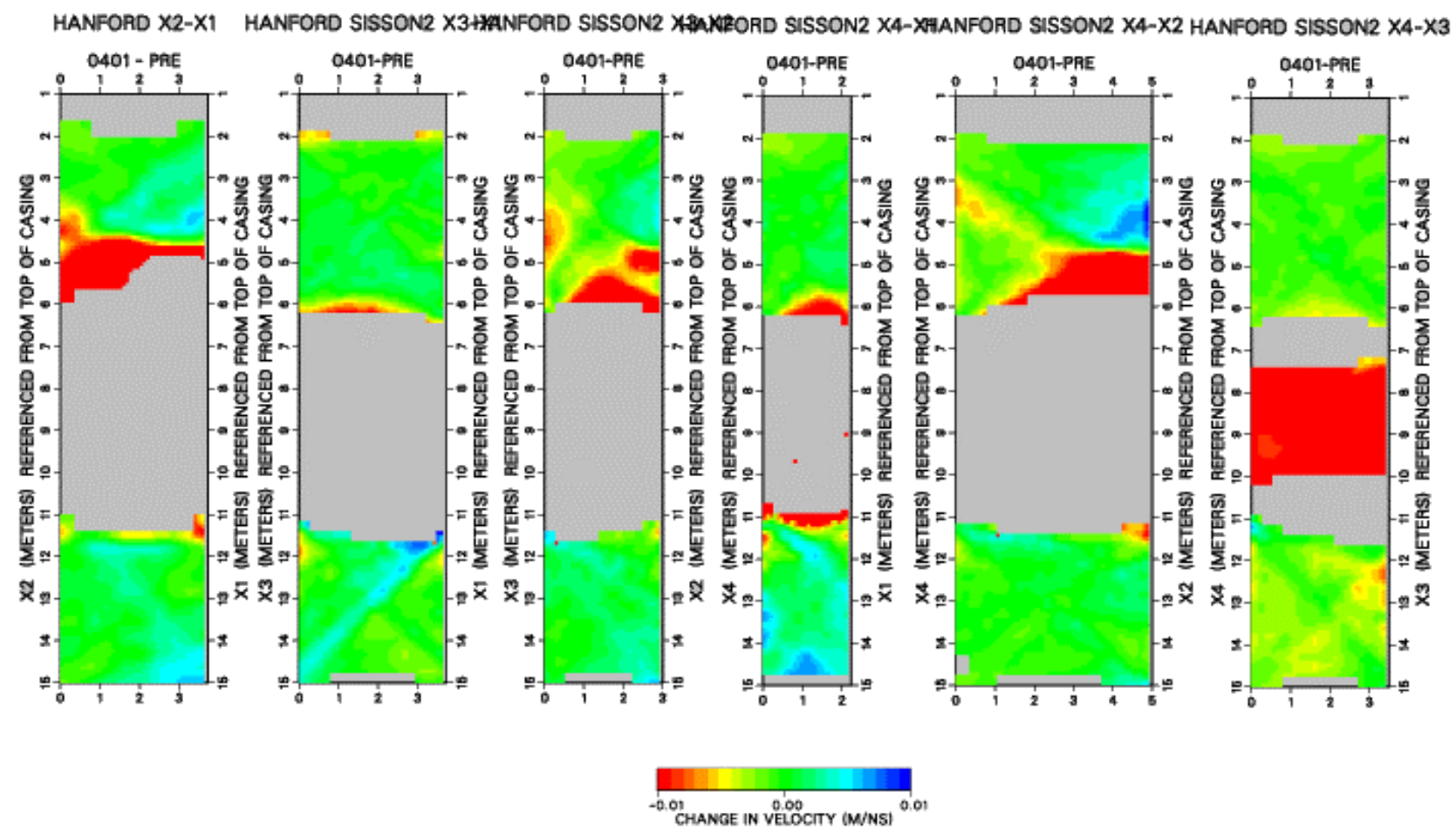

Figure 4.12. Change in Radar Velocities from the Baseline (2001) Between all Well Pairs After the Injection of all of the Sodium Thiosulfate

\subsection{Seismic}

Although at this time all of the seismic data have not been collected (there is one more seismic data collection to be made), the results to date are very surprising in their high quality for both the closespacing X wells and the long-offset work. Data acquired from the X1-X4 borehole pair have been processed, and the travel times have been inverted for the seismic-velocity structure. The same algorithm and parameters were used for this inversion of seismic data as were used for the radar data. Figure 4.14 shows the comparison of the radar and the seismic data estimates of the structure. 


\section{HANFORD X2-X1}

HANFORD SISSON2 X3-MANFORD SISSON2 X3HXRFORD SISSON2 X4-XANFORD SISSON2 X4-X2 HANFORD SISSON2 X4-X3
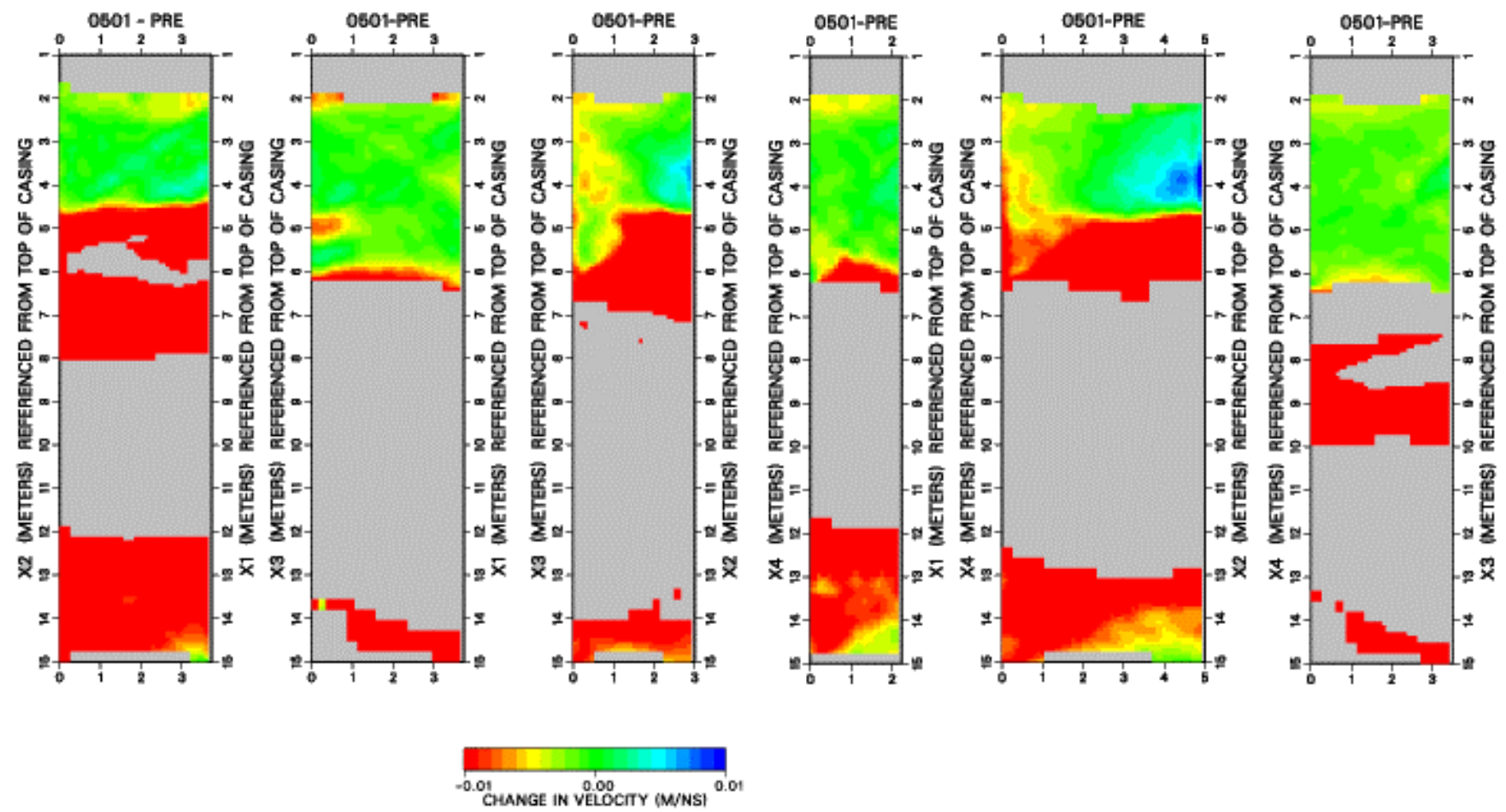

\section{Figure 4.13. Change in Radar Velocities from the Baseline (2001) Between all Well Pairs 9 Days After the Injection of all of the Fluids (sodium thiosulfate plus the follow-on river water injections)}

Note that the seismic velocities are quite low, just above the velocity of air. The seismic velocities resolve the same stratigraphy as the radar-velocity estimates; however, the high-radar-velocity layers coincide with the low-seismic-velocity layers and visa versa. This is most likely because electromagnetic wave velocities are high in air while the acoustic wave velocities are low in air. Therefore, in unsaturated material, the seismic waves should travel slowest in high-porosity material, and electromagnetic waves should travel fastest in high-porosity material. The velocity tomograms in Figure 4.14 appear to support this interpretation. 
HANFORD $\times 4-\times 1$

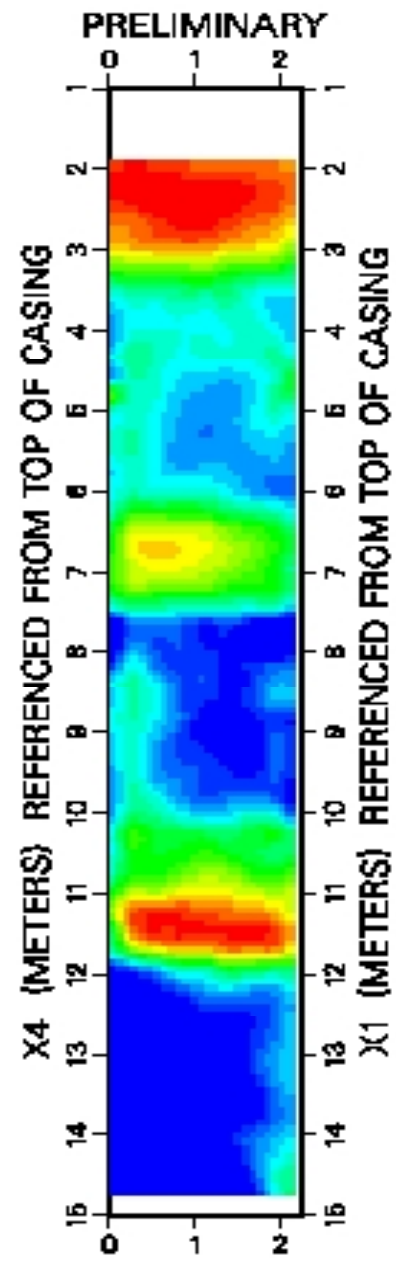

HANFORD $\times 1-\times 4$

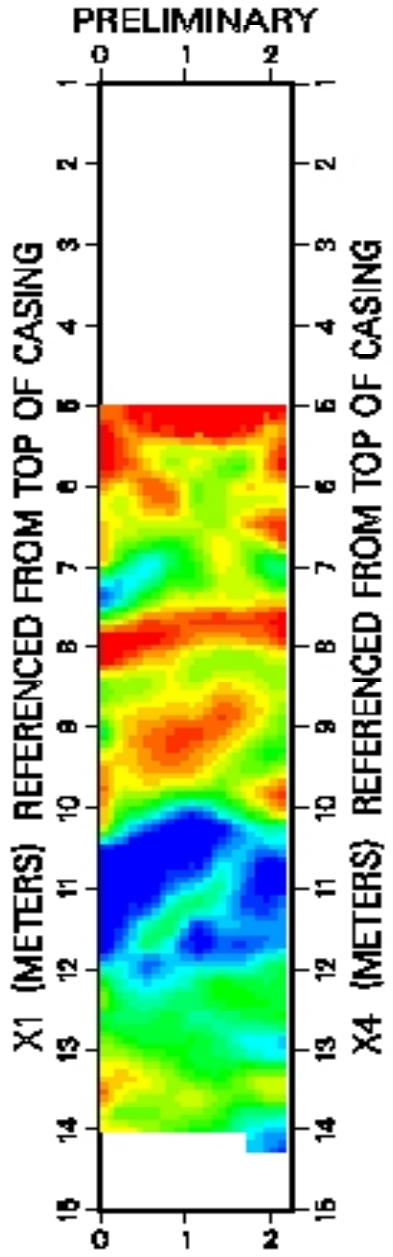

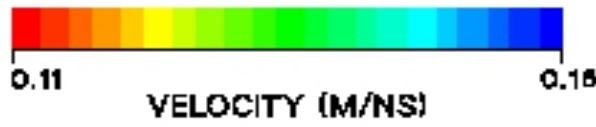

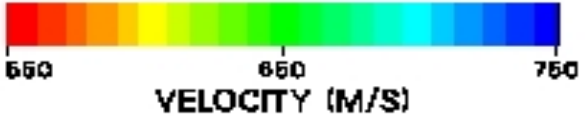

Figure 4.14. The Definition of Structure from Radar and Seismic; Note the Much Greater Details in the Structure Derived from the Seismic

Figure 4.15 and Figure 4.16 are data from the long offset seismic test. These data are quite surprising also in that sesimic data of such high frequency can be propagated so far in this vadose-zone environment. Figure 4.15 shows good energy up to 300 hertz. Figure 4.16 is a composite of the different levels, showing good $\mathrm{P}$-wave and $\mathrm{S}$-wave energy. This is very encouraging for future imaging at the tank scale. 


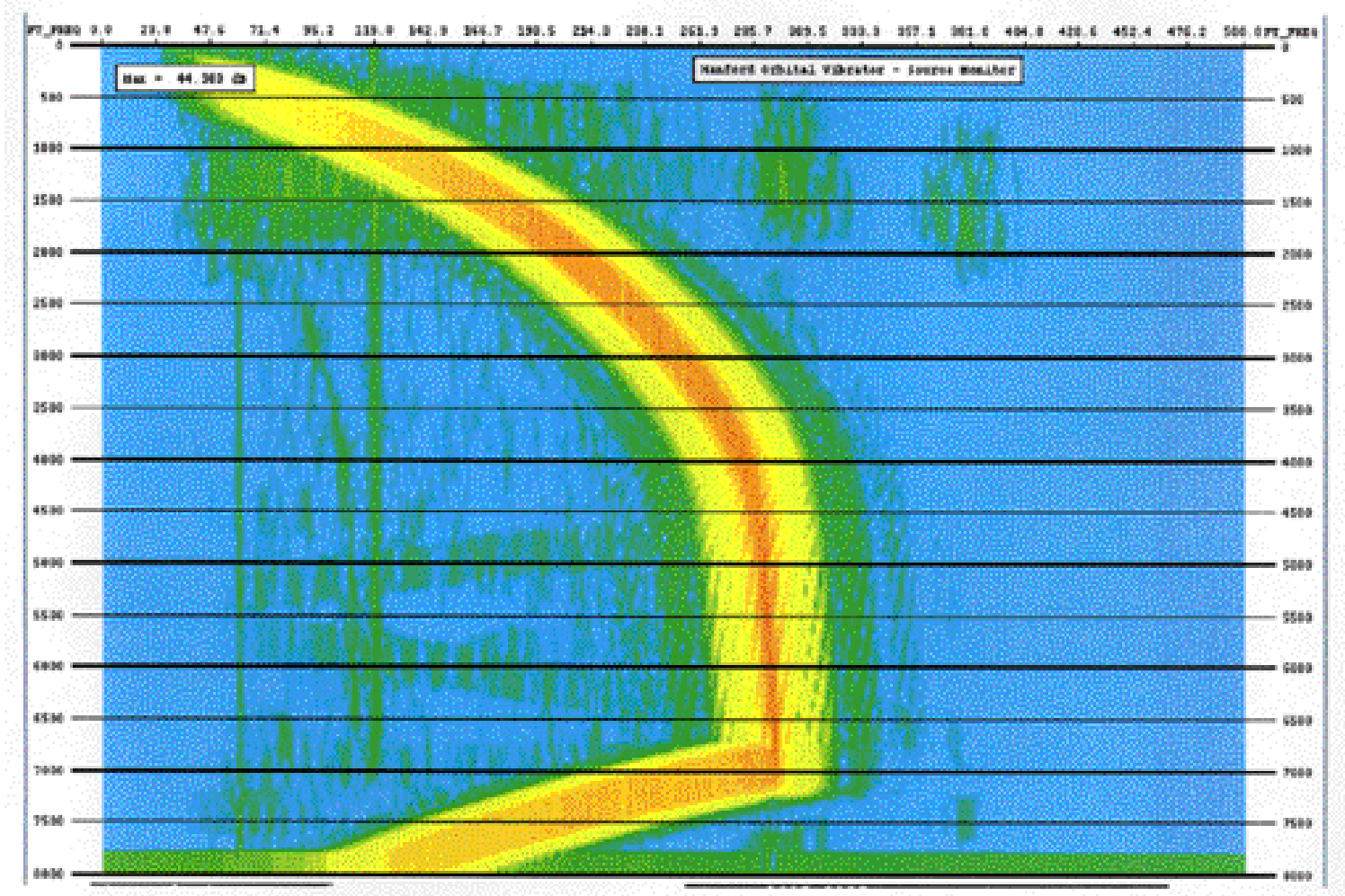

Figure 4.15. The Frequency Response as a Function of Time for the Seismic Source Used in the Large Offset Wells 


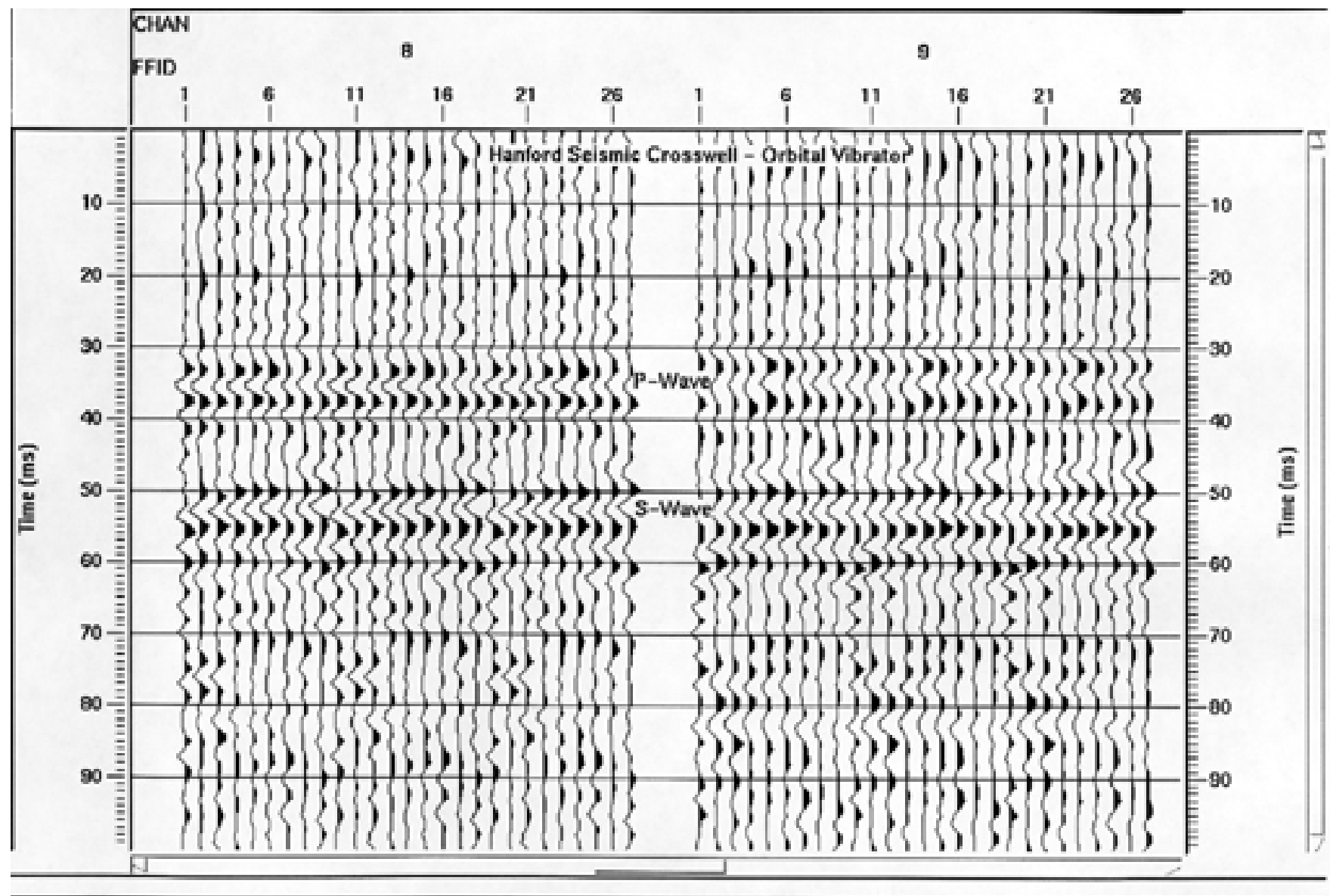

Figure 4.16. Example of Seismic Data at $19 \mathrm{~m}$ Through the Upper Vadose Zone Using a Seismic Source in the Range of 50 to 300 hertz 


\subsection{Summary}

Overall, the radar and seismic results were excellent. At the time of design of the experiments, we did not know how well these two methods could penetrate or resolve the moisture content and structure. It appears that the radar could easily go up to 5 , even $10 \mathrm{~m}$, between boreholes at $200 \mathrm{Mhz}$ and even farther (up to 20 to $30 \mathrm{~m}$ ) at $50 \mathrm{Mhz}$. The seismic results indicate that at several hundred hertz, a propagation of 20 to $30 \mathrm{~m}$ giving high resolution is possible. One of the most important results, however, is that together the seismic and radar are complementary in their properties estimation, the radar being sensitive to changes in moisture content primarily, and the seismic being primarily sensitive to porosity. Taken in a time lapse sense, the radar can show the moisture content changes to a high resolution, with the seismic showing high resolution lithology. To date, the significant results are:

Radar: Delineated geological layers 0.25 to $3.5 \mathrm{~m}$ thick with 0.25 -m resolution.

Delineated moisture movement and content with $0.25-\mathrm{m}$ resolution.

Compared favorably with neutron probe measurements.

Penetration up to $30 \mathrm{~m}$.

Radar results indicate that the transport of the river water is different from that of the heavier and more viscous sodium thiosulfate. It appears that the heavier fluids are not mixing readily with the in situ fluids, and the transport may be influenced by them.

Seismic: Delineated lithology at $0.25-\mathrm{m}$ resolution.

Penetration over $20 \mathrm{~m}$, with a possibility of up to 30 or more meters. 


\subsection{References}

Peterson, J. E., B.N.P. Paulsson. and T. V. McEvilly. 1985. "Application of algebraic reconstruction techniques to crosshole seismic data," Geophysics, 50, 1566-1580.

Topp, G. C., J. L. Davis, and A. P. Annan. 1980. "Electromagnetic determination of soil water content: Measurements in coaxial transmission lines," Water Resour. Res., 16, 574-582. 